\title{
Frontoorbital Advancement and Forehead Remodeling for Correction of Anterior Calvarial Craniosynostosis, Surgical Technique and Results in Low Economic Facilities: Benha Experience
}

\author{
MOHAMMED H. EL-TANTAWY, M.D.*; AHMED A. ARAB, M.D.* and MOHAMMED EL-SAYED, M.D.** \\ The Departments of Neurosurgery* and ENT**, Faculty of Medicine, Benha University, Benha, Egypt
}

\begin{abstract}
Background: Craniosynostosis is a congenital problem that affects brain development and causes disfigurement of the head and face. Anterior calvarial craniosynostosis involves the metopic and/or coronal sutures. The most accepted surgical correction involves frontoorbital advancement and forehead remodeling. Lack of knowledge about craniosynostosis, the need for equipped facilities in addition to the fear of complications from surgery led to delay in doing surgery at the optimum age, and with this delay more complex surgical techniques are needed, with a less favorable outcome.
\end{abstract}

Aim of the Study: In this study, we described our experience and technique in surgical correction of anterior calvarial craniosynostosis at Benha University Hospital using the frontoorbital advancement technique without the use of any expensive miniplates or helmets compensating the low socioeconomic standard of the community.

Study Design: This is a retrospective study case series of 15 patients, their ages ranged from 4 to 30 months. All patients have anterior calvarial craniosynostosis and were treated surgically using the frontoorbital advancement technique. Patients had been followed after surgery for a period of time ranged from 8 to 20 months during the years from March 2013 to December 2016.

Patients and Methods: Fifteen patients were included; four with pure metopic craniosynostosis, five with combined metopic and coronal, four patients with bilateral coronal and two with unilateral coronal. Patients were clinically and radiologically evaluated using CT scan skull with $3 \mathrm{D}$ reconstruction. Pre and post-operative scans as well as patient photographs have been compared and evaluated for the degree of correction of the relationship between the supra orbital bar and the cornea as well as the degree of correction of the deformity in the face and forehead.

Results: Out of 15 patients with craniosynostosis involved in this study, $11(73.3 \%)$ patients had achieved very good

\footnotetext{
Correspondence to: Dr. Ahmed A. Arab, E-Mail: arabneuro@gmail.com, ahmed.arab@fmed.bu.edu.eg
}

cosmetic and functional outcome, two patients (13.3\%) had an unsatisfactory cosmetic outcome in the form of irregularities in the shape of the skull that necessitated to do another surgery, one patient $(6.67 \%)$ had a bad cosmetic outcome, and one patient died in the early post-operative period.

Conclusion: Frontoorbital advancement with forehead remodeling is the best option for treating anterior calvarial craniosynostosis. For achieving better results surgery should be done at the optimum age and in well equipped medical center. Although using miniplates and helmets may help with the outcome, surgery can be performed with minimal resources in accordance with the economic state of the community with good results.

Key Words: Craniosynostosis - Frontoorbital remodeling Total calvarial remodeling.

\section{Introduction}

CRANIOSYNOSTOSIS is the premature closure of one or more of the skull sutures. It occurs as an isolated (simple) form or complex form in which multiple sutures are involved (syndromic) [1,2] .

Craniosynostosis disturbs the growth of the skull, affecting both cranial and facial bones, resulting in deformity. It is not only the deformity that matters, untreated cases may develop brain atrophy, increased intracranial pressure, mental retardation, ocular complications, and optic nerve atrophy [2].

\footnotetext{
List of Abbreviations:

MRI : Magneting Resonance Imaging.

CT Scan : Computerized Tomography Scan.

3D : Three Dimensional.

ICU : Intensive Care Unit.

CSF : Cerebro Spinal Fluid.

VP Shunt: Venticulo Peritoneal Shunt.
} 
Metopic and coronal sutures are commonly involved in this pathology following in their incidence only the saggital suture [3]

Anterior skull craniosynostosis involving the metopic and coronal sutures results in special shapes of the skull and face, trigonocephaly in metopic craniosynostosis, brachycephaly in bilateral coronal craniosynostosis, and anterior plagiocephaly in unilateral coronal craniosynostosis [4]

Recently, surgical correction of the metopic and coronal craniosynostosis involved frontoorbital advancement with forehead remodeling aiming to correct the shape of the skull and give adequate space for brain growth [5]

Lack of knowledge about craniosynostosis, the need for equipped facilities in addition to the fear of complications from such surgery, may be the cause of delay in doing such surgery at the optimum age. This delay may result in more complex surgical techniques and less favorable outcome [2-5]

In this study, we retrospectively describe our experience in surgical correction of anterior calvarial craniosynostosis at Banha University Hospital using the fronto orbital advancement technique without the use of any expensive miniplates or helmets compensating the low socioeconomic standard of the community.

\section{Patients and Methods}

Fifteen patients with anterior calvarial metopic and/or coronal craniosynostosis were surgically managed at Neurosurgery Department, Banha Faculty of Medicine, through the period from March 2013 to December 2016. Types of sutures involved and age at time of surgery are shown in (Table 1).

All patients were evaluated by history taking, general and neurological examination, and a local examination of the sutures, fontanellae and head circumference. All cases had been evaluated by a pediatrician to detect any other associated congenital anomalies. Patients also were ophthalmologically examined and fundoscopy was done.

Digital plain X-ray anteroposterior and lateral for the skull was done initially to all patients followed by CT scans with 3D reconstruction to ensure the diagnosis of the affected sutures and plan for surgery. MRI brain was done for all patients before surgery to exclude cerebral malformations or any other intracranial pathologies. Patients with intracranial pathologies were excluded from the study.

Patients were admitted 2 days before surgery for laboratory evaluation and cross matching of blood whenever needed for transfusion after surgery. Surgery was done under general anesthesia. Hypothermia was avoided by using sheets of cotton and plastic to wrap the limbs and trunk.

Removal of the synostosed suture with reshaping of the forehead and orbital advancement were done for all patients with some modifications depending on the sutures involved. The aim of surgery was to give the brain enough space for normal growth and to correct the deformity in the shape of the skull.

\section{Surgical technique:}

Before starting the surgery, protection of the cornea should be done by bilateral tarsorraphies and preoperative antibiotic was given to the patient.

Utilizing a bicoronal incision in a wavy or zigzag fashion was important to provide adequate exposure of the frontoorbital region and it has good cosmetic results with less postoperative scar.

The incision was infiltrated with diluted adrenaline saline $1 / 200000$ to minimize scalp bleeding. Then the scalp was dissected anteriorly in the frontal and temporal region in subgalial plan. The dissection stopped 1 finger breadth above the supra orbital rim. The posterior scalp flap was then dissected posteriorly till about $5 \mathrm{~cm}$ behind the coronal suture. The periostiumwas then dissected separately starting $1 \mathrm{~cm}$ behind the scalp incision line and continue anteriorly until we reached the supraorbital rim, where the supra orbital nerves and vessels were freed and dissected to preserve them.

The subperiosteal dissection was then extended to the periorbita where it was carefully dissected from superior and lateral wall of the orbit. Care was taken to avoid marked compression on the globe. Any tears to the periorbita were sutured immediately to prevent herniation of the orbital fat. Temporalis muscle was then dissected and reflected postero-inferiorly in subperiosteal plan using sharp dissection from below upwards to preserve its blood and nerve supply.

Keyhole burr hole was then made on each side just below the anterior end of the superior temporal line, exposing the frontal lobe dura above, periorbita 
below with the orbital roof in between. Another burr hole was made at the midline $1 \mathrm{~cm}$ above the nasion. Using the craniotome, osteotomy was done passing through the frontal compartment of the key holes and the midline burr holes. Frontal craniotomy was then completed by doing posterior osteotomy starting from midline at the coronal suture (if only the metopic suture was involved) and behind the coronal suture (if coronal suture was involved) and extend on each side of the greater sphenoid wing. The greater sphenoid wing was then drilled out all the way to the anterior clinoid. This step was very important to allow for growth at the mid face and orbit, then 2 lateral osteotomies was done to complete the removal of the frontal bone flap, leaving the supra orbital bar in plac.

If the metopic suture was involved certain steps were done to facilitate reconstruction of the triangular shaped supra orbital bar. At first, midline drilling of the synostosed metopic suture, from the inner side down to the anterior cranial fossa was done, leaving only thin outer cortex of bone. Then additional partial thickness bony cuts were made at the lateral edge of the supra orbital bar on both sides perpendicular to the roof of the orbit to facilitate remodeling and correction of the hypotelorism. Another bony cut was then made on both sides at the frontozygomatic suture passing through the lateral orbital wall utilizing the orbital component of the previously made key holes. Using a small osteotome, the orbital roof was cut $1.5 \mathrm{~cm}$ behind the supra orbital rim. Now the supra orbital bar could be easily displaced anteriorly and spreaded out laterally on each side. This reconfiguration was maintained using an intervening bone graft, designed to fit just between the lateral edge of supra orbital baranteriorly and the sphenoid posteriorly. The frontal bone flap was then reconstructed with removal of the coronal synostosed suture if it was involved. This was done by reversing the position of the frontal bone flap (posterior part in anterior position) or could be divided into 2 parts then placed again in a reverse pattern.

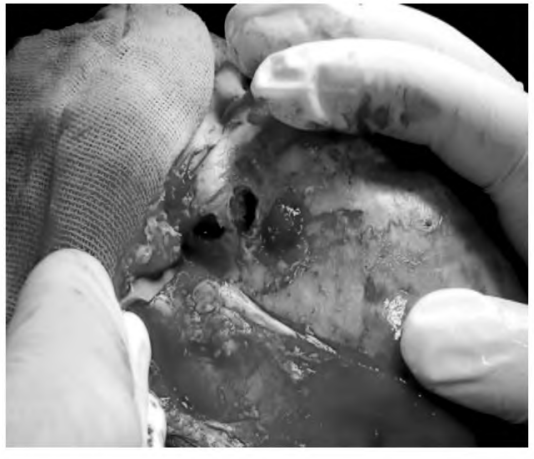

(A)

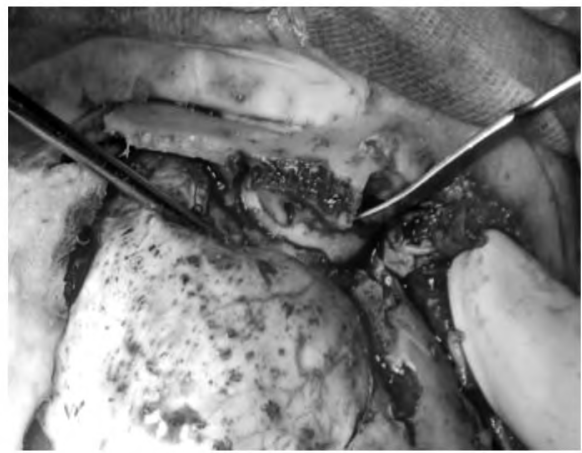

(B)

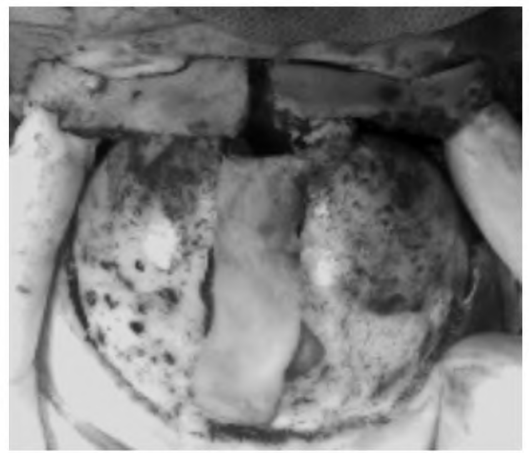

(C)

Fig. (1): Intra operative pictures showing part of the surgical technique. (A) Key hole at anterior end of the superior temporal line with 2 compartments; orbit below and the frontal lobe dura above with the orbital roof in between. (B) Superior cut in the orbital roof and lateral cut in the lateral orbital wall with drilling of the sphenoid. (C) Drilling the metopic suture in the midline with spreading out the lateral parts of the orbital bar, keeping the median part attached.

Radially oriented bony cuts were then made in the parietal bone to allow growth of the newly reshaped skull as one unit. Tiny holes were made in all bony parts and then the bony parts were secured in place together with absorbable sutures, leaving one $\mathrm{cm}$ width between edges, except at the advanced orbital bar in which we approximate the frontal bone to it and was secured with sutures without gap.

Patient with bilateral coronal craniosynostosis presented with widened biparietal diameter and frontal towering. Their surgical correction involved advancement of the orbital and frontal bone bilat- erally. In unilateral coronal craniosynostosis, surgical correction was done bilaterally with mild recession of the unaffected part and advancement of the affected one with bilateral removal of the synostosed coronal suture. The periostium was then replaced over the reshaped bone. Temporalis muscle was replaced adequately to prevent hollowing of the sphenoid area. The wound was then closed in 2 layers over a drain.

After surgery, the patients were placed in pediatric ICU usually for 48 hours, drain was usually removed by the 2 nd day or according to output, parents were informed about the swelling that it 
should subside after a few days. Patients were usually discharged at the 5 th day form surgery, they came for suture removal at the 12 th day postoperatively and followed regularly at 3,6,12 weeks then every 3 months for a year.

\section{Results}

The study involved 15 patients, all of them had anterior calvarialcraiosynostosis. Four patients had pure metopic craniosynostosis $(2$ males and 2 females) with trigonocephaly, five patients had combined metopic and bilateral coronal craniosynostosis ( 3 males and 2 females), four patients had pure bilateral coronal craniosynostosis ( 3 males and 1 female), and two female patients only had unilateral coronal craniosynostosis. Their ages at time of surgery and follow-up length are shown in (Table 1).

Clinically, the main complaint at the 1 st visit for all patients was deformity and overriding of the skull and face observed by their parents and pediatrician. Silver-beaten appearance of the skull as radiological finding has been found in 10 patients $(66.6 \%)$ of our study in the preoperative assessment. Funds examination was normal in all patients except only one patient with multiple cranial craniosynostosis that has been delayed in 1 st presentation at 30 months.

Frontoorbital remodeling was done in 4 patients with metopic craniosynostosis. Five patients with combined metopic and bicoronal craniosynostosis had total calvarial correction with orbital advancement, standard frontoorbital advancement with forehead remodeling was done in 4 patients with bilateral coronal craniosynostosis, and the last 2 patients with unilateral coronal craniosynostosis had unilateral frontoorbital advancement with forehead remodeling with the use of calvarial graft in the recessed side only.

The average operating time was 4 hours. We used a high speed drill and bone cutting craniotome in all cases to make surgery faster and easier. Blood transfusion was used in 12 (80\%) out of 15 patients. The most common complications that had been encountered during surgery was dural tear that necessitated immediate surgical repair with absorbable sutures in 6 patients (40\%). We found early suturing of the dura very important to keep the CSF protecting the brain during manipulation.
For all patients, total hospital stay ranged from 5-7 days, mean (5.8 days). In the 1 sttwodays patients were kept in pediatric ICU then they were discharged to the ward after that.

One patient (6.7\%) had CSF leak post-operative that stopped spontaneously in 2 days, two patients $(13.3 \%)$ had superficial wound infection that improved with medical treatment. The only case of mortality in our study was in 4 months old infant with metopic and coronal craniosynostosis that arrested during surgery because of hypothermia and acidosis, after resuscitation the patient transferred to pediatric ICU on mechanical ventilation for 3 days and arrested again. No intracranial hemorrhage or post-operative fits has been encountered in our study.

Follow-up period ranged from (8-20 months) mean (13.2 months). The mean age at time of surgery was (10.1) months. Fourteen patients $(93.3 \%)$ had a 3D CT scan on skull at 6 months of follow-up period to be compared with the preoperative ones to determine the degree of bony union and if there is any evidence of resynostosis.

Out of 15 patients with craniosynostosis involved in this study, 11 patients $(73.3 \%)$ had achieved very good cosmetic and functional outcome, as achieved by comparing pictures of pre and post-operative and by parent satisfaction. In those 11 patients the relationship between the cornea and supraorbital rim improved dramatically. Functional outcome had been determined by normal milestones in relation to age. Two patients in our study $(13.3 \%)$ one with combined metopic and Bicoronal craniosynostosis and the other one unilateral coronal had an unsatisfactory cosmetic outcome in the form of irregularities in the shape of the skull that necessitated to do another surgery on them. The one was due to the rapid reunion of pathological sutures. The other one was due to early slippage of sutures connecting the bony parts. One patient $(6.67 \%)$ had a bad cosmetic outcome due to late surgical interference at age of 30 months because of negligence of the family and involvement of more than 2 sutures that necessitated another surgery.

Those patients who underwent redo surgery is still followed, and their final outcome is not included in this study. 


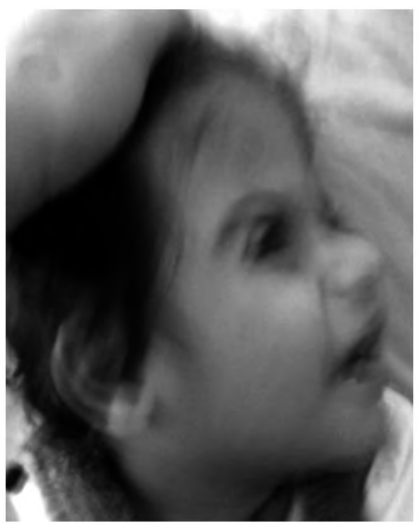

(A)

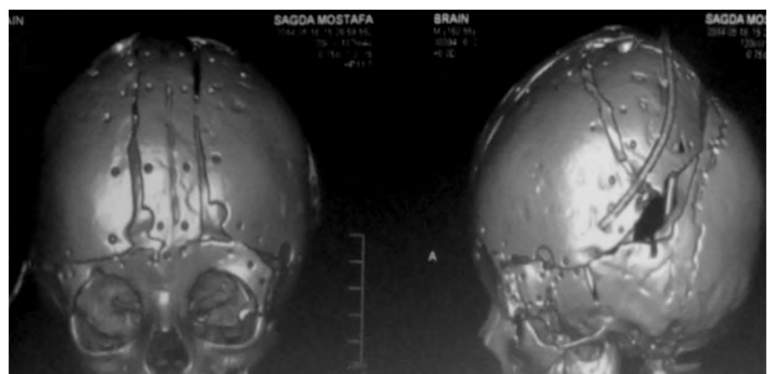

(D)

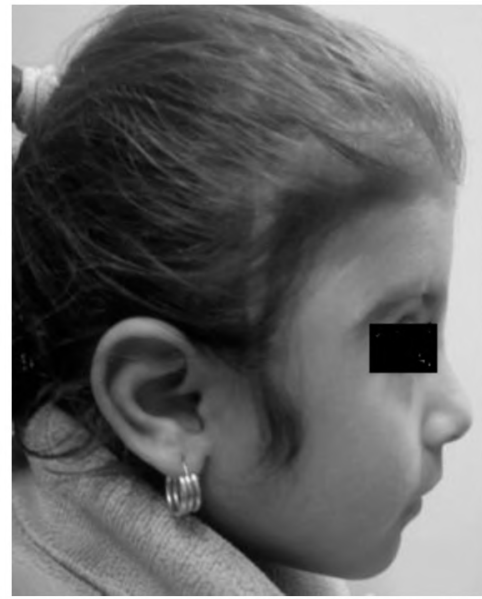

(F)

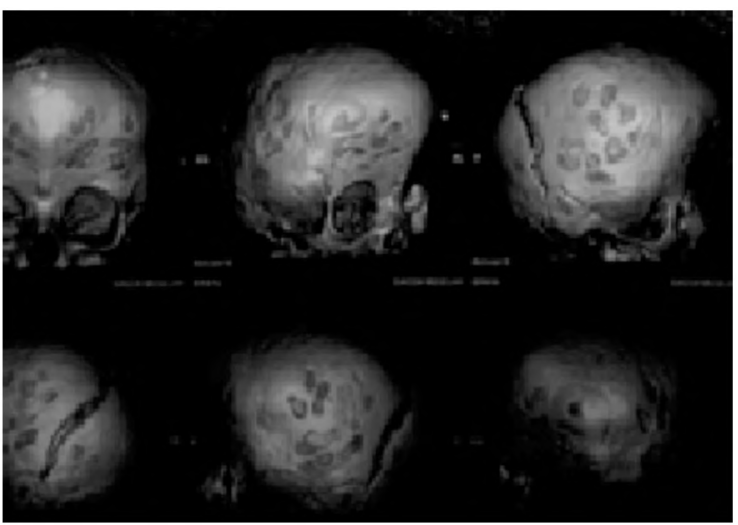

(B)

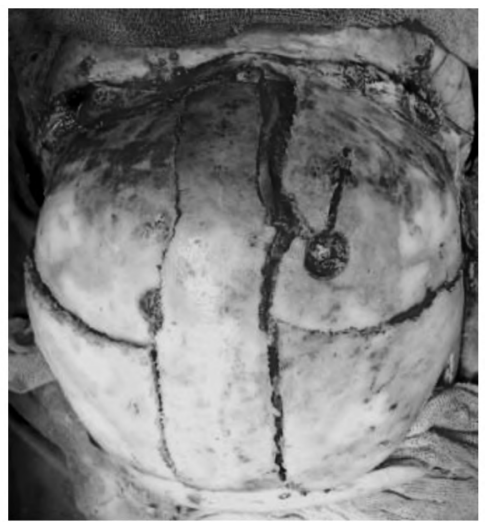

(C)

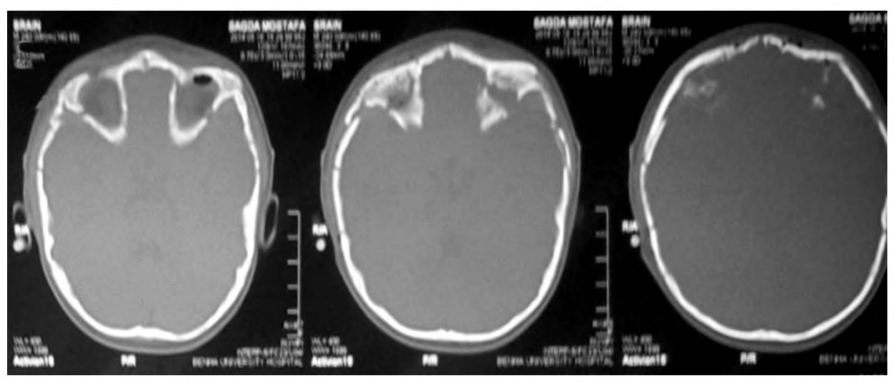

(E)

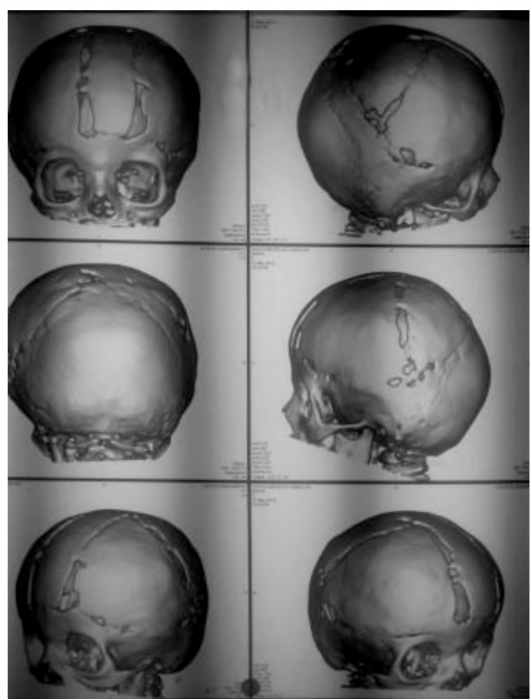

(H)

Fig. (2): A patient with bilateral coronal craniosynostosis. (A): Pre-operative photograph lateral projection, (B): Pre-operative skull 3D CT reconstruction showing silver-beaten appearance and frontal towering, (C): Intraoperative picture showing the orbital advancement and frontal remodling, (D): Immediate post-operative 3D CT scan showing the bony cuts and frontal advancement, (E): CT axial cuts showing the bony cuts in the superior and lateral wall of the orbit, (F,G): Patient photograph at end of follow-up period showing good deformity correction, (H): 3D CT skull reconstruction at end of follow-up. 

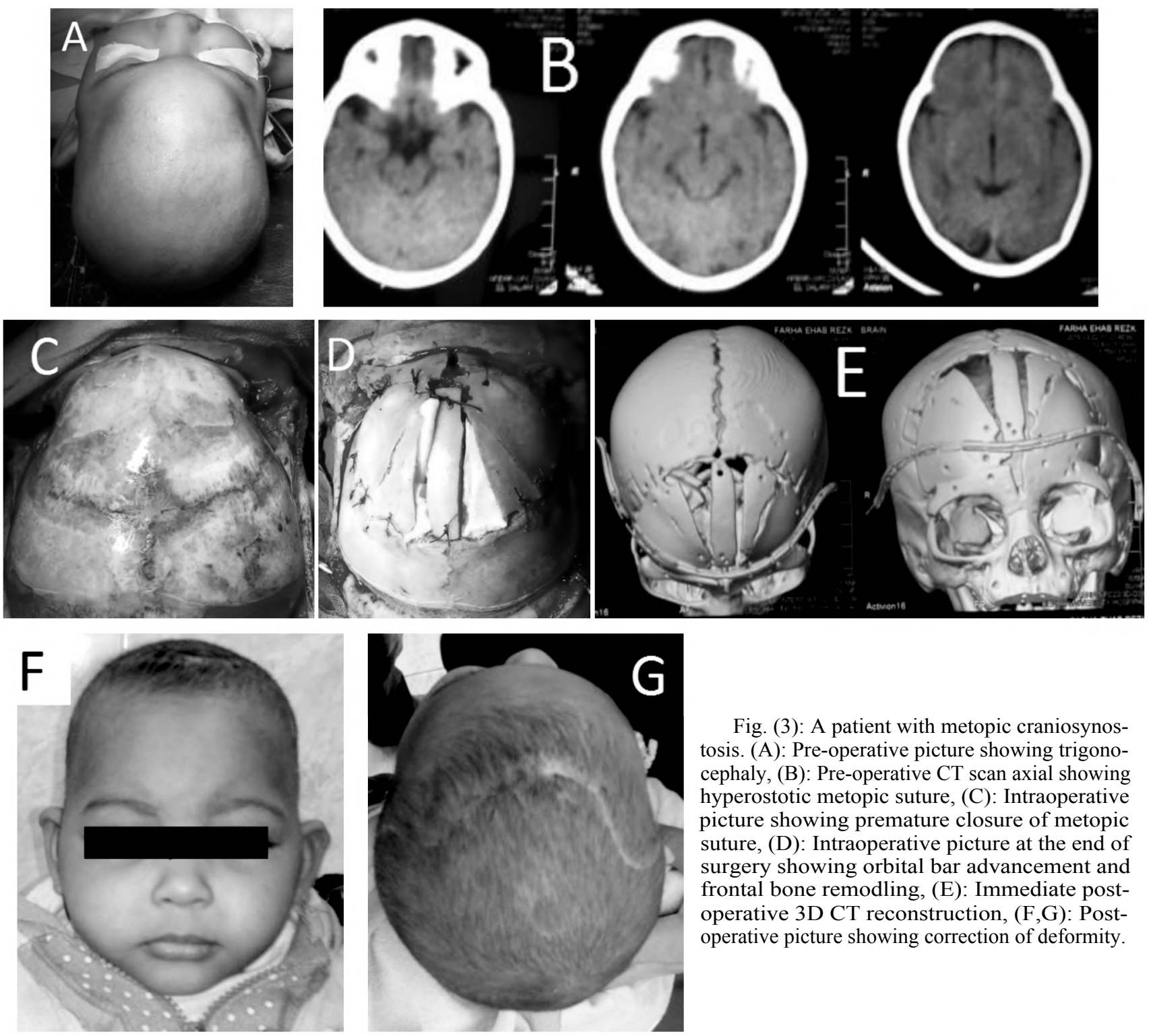

Fig. (3): A patient with metopic craniosynostosis. (A): Pre-operative picture showing trigonocephaly, (B): Pre-operative CT scan axial showing hyperostotic metopic suture, $(\mathrm{C})$ : Intraoperative picture showing premature closure of metopic suture, (D): Intraoperative picture at the end of surgery showing orbital bar advancement and frontal bone remodling, (E): Immediate postoperative 3D CT reconstruction, $(F, G)$ : Postoperative picture showing correction of deformity.

Table (1): Details of individual cases.

\begin{tabular}{lccllc}
\hline $\begin{array}{l}\text { Case } \\
\text { no }\end{array}$ & $\begin{array}{c}\text { Age at time } \\
\text { of surgery } \\
\text { (months) }\end{array}$ & Gender & $\begin{array}{l}\text { Sutures } \\
\text { affected }\end{array}$ & $\begin{array}{c}\text { Type } \\
\text { of surgery }\end{array}$ & $\begin{array}{c}\text { Length of } \\
\text { follow-up } \\
\text { period (months) }\end{array}$ \\
\hline 1 & 7 & M & Metopic & FOR & 14 \\
2 & 9 & M & Metopic & FOR & 20 \\
3 & 6 & F & Metopic & FOR & 12 \\
4 & 9 & F & Metopic & FOR & 10 \\
5 & 6 & M & Metopic and bilateral coronal & TCC + OA & 14 \\
6 & 4 & F & Metopic and bilateral coronal & TCC + OA & 8 \\
7 & 7 & M & Metopic and bilateral coronal & TCC + OA & 12 \\
8 & 8 & F & Metopic and bilateral coronal & TCC + OA & 16 \\
9 & 30 & M & Metopic and bilateral coronal & TCC + OA & 20 \\
10 & 10 & F & Bilateral coronal & St FOA + FhR & 12 \\
11 & 12 & M & Bilateral coronal & St FOA + FhR & 14 \\
12 & 9 & M & Bilateral coronal & St FOA + FhR & 10 \\
13 & 8 & M & Bilateral coronal & St FOA + FhR & 12 \\
14 & 12 & F & Unilateral coronal & Uni. FOA + FhR & Uni. FOA + FhR \\
15 & 14 & F & Unilateral coronal & & 12 \\
\hline
\end{tabular}

FOR : Frontoorbitalremodling.

TCC + OA : Total Calvarial Correction + Orbital Advancement.

St FOA + FhR : Standard Frontoorbital Advancement + Forehead Remodling.

Uni. FOA + FhR : Unilateral Frontoorbital Advancement + Forehead Remodling. 
Table (2): Surgical outcome of the 15 patients included in this study.

\begin{tabular}{lcccc}
\hline \multirow{2}{*}{ Category } & \multicolumn{4}{c}{ Outcome } \\
\cline { 2 - 5 } & Good & Unsatisfactory & Bad & Died \\
\hline Metopic & 4 & 0 & 0 & 0 \\
Metopic and bilateral coronal & 2 & 1 & 1 & 1 \\
Bilateral coronal & 4 & 0 & 0 & 0 \\
Unilateral coronal & 1 & 1 & 0 & 0 \\
\hline Total & $11(73.3 \%)$ & $2(13.3 \%)$ & $1(7.6 \%)$ & $1(6.7 \%)$ \\
\hline
\end{tabular}

\section{Discussion}

Craniosynostosis is the premature closure of one or more of the cranial sutures. It occurs in 1 of 2000-2500 live births. More than $90 \%$ of craniosynostosis patients occur spontaneously affecting one or more suture. Less than $10 \%$ of cases occur in syndromic forms, inherited as an autosomsal dominant trait [1-3].

The most commonly affected suture is the saggital suture, about $50 \%$ of non syndromic cases. This is followed by metopic then unilateral coronal craniosynostosis. The bilateral coronal affection is most commonly involved in syndromic cases [3].

The exact etiology of simple (non syndromic) craniosynostosis is unknown, however, some risk factors like prenatal intake of valproate, underweight, preterm delivery and early use of v-p shunt for congenital hydrocephalus may be associated [6].

Major skull sutures (saggital, coronal, lambdoid, and metopic) are responsible mainly for the normal shape and configuration of the skull and face. When one or more of these sutures are affected by early closure, cranial deformity and restriction of growth will occur with the potential increase in intracranial pressure $[2,3]$.

According to Virchow's low, the skull grows parallel to the closed suture, not perpendicular to it. That's why in saggital craniosynostosis, the head usually acquire elongated shape in the anteroposterior diameter (dolicocephalic head) while in bilateral coronal craniosynostosis the head widens in the transverse diameter (brachycephaly). Unilateral coronal craniosynostosis is more complex, although involving one side only. It is characterized by unilateral forehead flattening and elevation of the same side orbital rim with traction of the root of the nose toward the affected side, giving characteristic shape (called anterior plagiocephaly) to the skull [3]
Early closure of the metopic suture, which closes normally very early in life, causes triangular shape of the forehead (trigonocephaly). This is usually associated with hypotelorism [7]

Increased intracranial pressure is a potential risk in syndromic craniosynostosis, although it is still a concern in non syndromic cases [8,9]. Elevated intracranial pressure in our study has been monitored by fundus examination and the characteristic silver beaten appearance of the inner table of the skull. Only one patient $(6.7 \%)$ had papillodema in our study. This low percentage is due to the fact that papillodema, as a sign of increased intracranial pressure, will appear only in patients with multiple closed sutures [9]. On the other hand silver beaten appearance has been found in $10(66.7 \%)$ patients. This is usually caused by gyral indentation of the inner table of the skull and it indicates also localized increased intracranial pressure [9]. In a study done by Wall et al., $44 \%$ of patients found to have increased intracranial pressure as diagnosed by invasive intracranial pressure monitoring. The study was done in 39 patients with non syndromic craniosynostosis [8]. In another study done by Eley et al., they found high or borderline intracranial pressure in $70 \%$ of patients with non syndromic craniosynostosis. They concluded that, the incidence of increased intracranial pressure in non syndromic craniosynostosis is underestimated in the literature and it should be considered as an important issue in treating those patients [9].

The aim from the surgical correction of craniosynostosis is to give adequate intracranial pressure and volume to allow the brain to expand normally so that minimizing the cognitive sequel that may occur from chronic increase intracranial pressure. Also to regain the normal shape of the skull to prevent psychological impact on patients upon entering the school due to the abnormal shape of the head $[10,11]$.

The best time of doing surgical correction in craniosynostosis is still a debatable issue in the 
literature as it depends on many factors. Simple and minimally invasive maneuvers can be done as early as 3 months, while complex surgical correction usually postponed to the age between 6 to 8 months. Surgical correction before 6 months of age, although possible, it carries the anesthetic and surgical risk to the newborn and needs as well equipped medical center. Between 6 and 8 months, surgery has the advantage of increase osseous heeling, softer bone to reshape and increase tolerance of patient to blood loss during surgery. Delaying the surgery after 1 year of age carries the risk of decrease intellectual development [12]. In our study, the mean age of patients at time of surgery was 10 months (ranging from 4 to 30 months). The only case of mortality in this study was 4 months old baby due to acidosis induced hypothermia, and the surgical results of the 30 months old patient was bad due to his hard bone and involvement of more than one suture.

Different types of surgical correction had been used by neurosurgeons, varying from the minimally invasive endoscopic suturectomy with the use of post-operative molding helmet, to open calvarial reconstruction [13]. Other authors advocated suturectomy with spring implantation and cranial distraction [14].

The choice of individual type of surgery depends mainly on age of the patient, suture involved, socioeconomic standard of the parents and facilities at surgical center $[\mathbf{2 , 1 3 , 1 4 ]}$. In our study no helmets were used nor mini plates due high expense on parents, this study described our surgical experience in treating patients with coronal and metopic craniosynostosis. Surgical correction of these sutures involved reshaping the anterior half of the skull convexity from the coronal suture to the orbital rim (frontoorbital remodeling), then orbital band advancement was the second step. This correction involved lateral extension of the coronal sutures all the way done to the greater wing of the sphenoid ridge at the skull base. We found this technique facilitates global fashioning and allow large correction of the orbital rim and forehead. This technique has been utilized in many studies $[\mathbf{1 0 , 1 1}$, 15-17].

Wide strip suturectomy was advocated by some other authors, relying only on brain growth for skull expansion only, without correction of the deformed skeleton [18]. Although possible and simple but it carried higher incidence of resynostosis with little effect on face and forehead development [19].
In this study 11 patients $(73.3 \%)$ achieved very good cosmetic outcome, 2 patients $(13.3 \%)$ had an unsatisfactory outcome, and one patient had bad cosmetic results. Qualitative assessment depended on comparing pre and post-operative CT skulls in the follow-up period, through assessment of the relationship of the supra orbital rim with the cornea. El-Sadek advocated more quantitative way of assessment through comparing the post-operative longitudinal orbital projection in post-operative CT scans with the pre-operative longitudinal orbital projection by measuring the degree of recession of the supra orbital rim in relation to the cornea [5].

Koh et al., reported good results in using supra orbital bar advancement with repositioning of different frontal and parietal bone segments, and satisfactory results were reported by Teng et al., using the same technique [16]. In our study, the orbital bar was not removed completely, as its median part was not separated from the nasion while the lateral part was advanced anteriorly using our new technique by separating lateral and superior orbital walls and securing their position by small bone fragment and absorbable suture.

For best results, an author advocated the use of biodegradable miniplates for optimal reconstruction, [20] and other one used dental wires [4]. Lo et al., found that the rigid plate fixation specially at the nasion is superior in stability for supra orbital bar advancement than non rigid suture fixation [21]. Our patients in this study could not afford for expensive biodegradable plates or dental wires, we found non rigid sutures reliable and economic way with good results, despite the claim for better outcome with usage of miniplates and helmets [25]

Every effort should be made to minimize blood loss during this surgery. We used high speed drills and craniotome to fasten process of bone cutting and minimize blood loss, and so $(80 \%)$ of our patients needed blood transfusion during surgery. An average of $216 \mathrm{cc}$ of packed RBCS has been used in those patients. Comparable results were found in other studies [22-24]. Temperature regulation during surgery is a very important issue in this kind of surgery, acidosis induced hypothermia may be fatal to infants. Thermal blankets are widely used to control temperature during surgery $[4,23]$ We used instead cotton sheets to wrap limbs of the patients then covered with plastic sheets. CSF leak due to dural tear from bony dissection occurred in one patient $(6.7 \%)$, and wound infection in 2 patients (13.3\%), other studies showed comparable rates of complications $[\mathbf{4 , 2 3}]$. 


\section{Conclusion:}

Frontoorbital advancement with forehead remodeling is the best option for treating anterior calvarial craniosynostosis. For achieving better results surgery should be done at the optimum age and in well equipped medical center. Although using miniplates and helmets may help in the outcome, surgery can be performed with minimal resources in accordance with the economic state of the community with good results.

\section{Acknowledgment:}

The authors thank all included children and their parents.

\section{Funding:}

This study had no funding from any resource.

\section{Competing interests:}

The authors declare that they have no conflict of interest.

\section{Ethical approval:}

This research accepted by Research Ethics Committee (REC) of Faculty of Medicine, Benha University (Chairman: Prof/Ibrahim El-Gendy).

All procedures performed in studies involving human participants were in accordance with the ethical standards of the institutional and/or National Research Committee and with the 1964 Helsinki declaration and its later amendments or comparable ethical standards. A written informed consent was obtained from each patient after explaining all steps of this study.

\section{Authors' contributions:}

Mohammed El-Tantawy and Ahmed Arab performed the clinical part of the study, Mohammed El-Tantawy, Ahmed Arab, and Mohammad ElSayed analyzed the data and wrote the paper with meticulous revision.

\section{References}

1- FRENCH L.R., JACKSON I.T. and MELTON L.J. III. A population-based study of craniosynostosis. J. Clin. Epidemiol., 43: 69-73, 1990.

2- PUENTE-ESPEL J., RIOS-LARA Y. LOPEZ, MORENOÁLVAREZ and MOREL-FUENTES: Craniosynostosis: A multidisciplinary approach based on medical, social and demographic factors in a developing country. Rev. Med. Hosp. Gen. Méx., 79 (4): 230-9, 2016.

3- GOVERNALE LANCE S.: Craniosynostosis. Pediatric Neurology, 53: 394-401, 2015.

4- EHTESHAM U.H., AYESHA A., ATIF K., SARMAD T.M., et al.: Fronto-Orbital Advancement and Total CalvarialRemodelling for Craniosynostosis. Journal of the
College of Physicians and Surgeons Pakistan, Vol. 24 (2): 118-22, 2014

5- EL-SADEK A.N.: Frontoorbital advancement in coronal suture craniosynostosis: A quantitative pre-operative assessment. Annals of Pediatric Surgery, Vol. 7 No. 4. 139-45, 2011.

6- SINGH R.P., DHARIWAL D., BHUJEL N., et al.: Role of parental risk factors in the etiology of isolated nonsyndromic metopic craniosynostosis. Br. J. Oral. Maxillofac. Surg., 48: 438-42, 2010.

7- LAJEUNIE E., Le MERRER M., MARCHAC D., et al.: Syndromal and non-syndromal primary trigonocephaly: analysis of a series of 237 patients. Am. J. Med., 75: 211$-5,1998$.

8- WALL S.A., THOMAS G.P., JOHNSON D., et al.: The pre-operative incidence of raised intracranial pressure in non syndromic sagittal craniosynostosis is underestimated in the literature. J. Neurosurg. Pediatr., 14: 674-81, 2014.

9- ELEY K.A., JOHNSON D., WILKIE A.O., JAYAMOHAN J., RICHARDS P. and WALL S.A.: Raised intracranial pressure is frequent in untreated nonsyndromicunicoronalsynostosis and does not correlate with severity of phenotypic features. Plast. Reconstr. Surg., 130: 690e697e, 2012.

10- ADAMO M.A. and POLLACK I.F.: Current management of craniosynostosis. Neurosurg. Quart., 19: 82-7, 2009.

11- PERSING J.A.: MOC-PS(SM) CME article: Management considerations in the treatment of craniosynostosis. Plast. Reconstr. Surg., 121 (4 Suppl): 1-11, 2008.

12- PATEL A., YANG J.F., HASHIM P., et al.: The impact of age at surgery on long-term neuropsychological outcomes in sagittal craniosynos-tosis. Plast. Reconstr. Surg., 134: 608e-17e, 2014

13-BERRY-CANDELARIO J., RIDGWAY E.B., GRONDIN R.T., ROGERS G.F. and PROCTOR M.R.: Endoscope assisted strip craniectomy and postoperative helmet therapy for treatment of craniosynostosis. Neurosurg. Focus, 31: E5, 2011.

14- LAURITZEN C.G., DAVIS C., IVARSSON A., SANGER C. and HEWITT T.D.: The evolving role of springs in craniofacial surgery: The first 100 clinical cases. Plast. Reconstr. Surg., 121: 545-54, 2008.

15-HANSEN M. and MULLIKEN J.B.: Frontal plagiocephaly: Diagnosis and treatment. Clin. Plast. Surg., 21: 543-53, 1994.

16- KOH K.S., KANG M.H., YU S.C., PARK S.H. and RA Y.S.: Treatment of nonsyndromic bilateral coronal synostosis using a multiple bone flap rotation-reposition technique. J. Craniofac. Surg., 15: 603-8, 2004.

17-MUHLBAUER W., ANDERL H., SCHMIDT A., HEECKT P., ZENKER J., SCHAARSCHMIDT B., et al.: Asymmetrical cranio orbital facial stenosis. Ann. Plast. Surg., 26: 45-50. Discussion 50-51, 1991.

18- PODDA S., WOLFE S.A., KORDESTANI R.K., PANCHAL J. and VELA G.: Craniosynostosis management. Medscape. 2008 [cited 27 th September 2011]. Available from http://emedicine.medscape. com/article/1281182overview\#a30. 
19- WILLIAMS J.K., ELLENBOGEN R.G. and GRUSS J.S. State of the art in craniofacial surgery: Nonsyndromiccraniosynostosis. Cleft. Palate Craniofac. J., 36: 471-85, 1999.

20- SERLO W.S., YLIKONTIOLA L.P., VESALA A.L., KAARELA O.I., IBERT T. and SANDOR G.K.: Effective correction of frontal cranial deformities using biodegradable fixation on the inner surface of cranial bones during infancy. Childs Nerv. Syst., 23: 1439-45, 2007.

21- LO L.J., MARSH J.L., YOON J. and VANNIER M.W.: Stability of fronto-orbital advancement in nonsyndromic bilateral coronal synostosis: A quantitative threedimensional computed tomographic study. Plast. Reconstr. Surg., 98: 393-405. Discussion 406-9, 1996.

22- WHITE N., MARCUS R., DOVER S., SOLANKI G.,
NISHIKAWA H., MILLAR C., et al.: Predictors of blood loss in fronto-orbital advancement and remodelling. J. Craniofac. Surg., 20: 378-81, 2009.

23- CZERWINSKI M., HOPPER R.A., GRUSS J., et al.: Major morbidity and mortality rates in craniofacial surgery: An analysis of 8101 major procedures. Plast. Reconstr. Surg., 126: 181-6, 2010

24- FEARON J.A. and WEINTHAL J.: The use of recombinant erythropoietinin the reduction of blood transfusion rates in craniosyn-ostosis repair in infants and children. Plast. Reconstr. Surg., 109: 2190-6, 2002.

25- KOVÁCS A.F., SAUER S.N., STEFENELLI U. and KLEIN C.: Growth of the orbit after fronto orbital advancement using non rigid suture versus rigid plate fixation technique. J. Pediatr. Surg., 43: 2075-81, 2008.

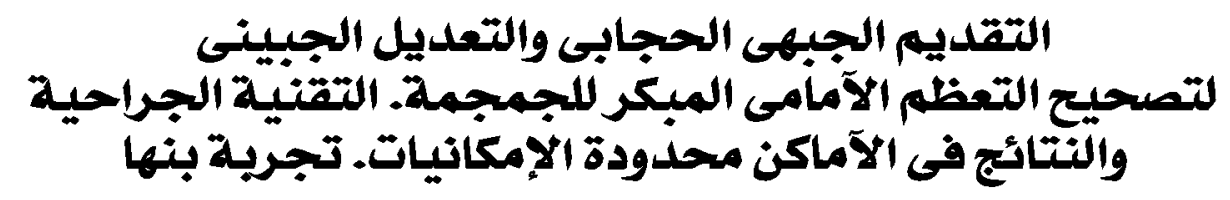

الخفية: التعظم المبكر للجمجمة هو مشكلة خلقية تؤثر على نمو الدماغ وتسبب تشوه بالرآس والوجه، ويشمل التعظم الآمامى التعظم

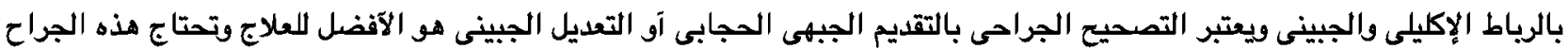

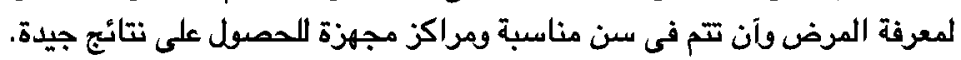
الهدف: تصف هذه الدراسة تجربتا وتقنيتنا الجراحية فى التصحيح الجراحى للتعظم الآمامى المبكر الجمجمة بلون إستخدام الثرائح

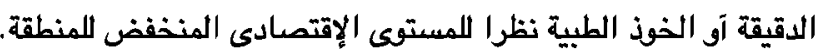

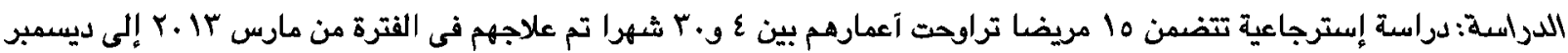

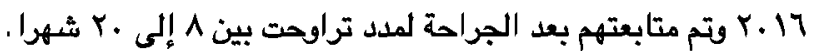

المرضى والطرق: تضمنت الدراسة ما مريضا، آربعة مرضيى لديهم تعظم بالرباط الجيني وخمسة لديهم تعظم بالرباط الجبينى والإكليلى وآربعة مرضى بالرياط الإكليلى على الجانبين ومريضين بالرياط الإكليلى على جانب واحد وتم إجراء الجراحة لهم وتقييمهم بالتصسن فى الشكل

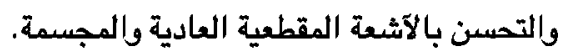

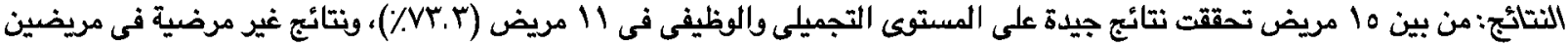

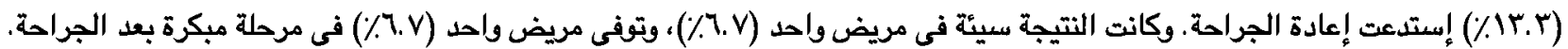

الإستتماج: التقديم الجبهى الحجابى والتعديل الجبينى لتصحيح التعظم الآمامى المبكر للجمجمة هو آفضل الخيارات الجراحية في التعظم المبكر للرباط الجبينى والإكليلى ويمكن الحصل على نتائج جيدة حتى بلدف إستخدام الثرائح الدقيقة والخوذ الطبية فى الآماكن محدوة 